\title{
Residual Fragments after Percutaneous Nephrolithotomy
}

\author{
Kaan Özdedeli, Mete Çek \\ Department of Urology, Faculty of Medicine, Trakya University, Edirne, Turkey
}

\begin{abstract}
Clinically insignificant residual fragments (CIRFs) are described as asymptomatic, noninfectious and nonobstructive stone fragments ( $\leq 4 \mathrm{~mm})$ remaining in the urinary system after the last session of any intervention (ESWL, URS or PCNL) for urinary stones. Their insignificance is questionable since CIRFs could eventually become significant, as their presence may result in recurrent stone growth and they may cause pain and infection due to urinary obstruction. They may become the source of persistent infections and a significant portion of the patients will have a stone-related event, requiring auxilliary interventions. CT seems to be the ultimate choice of assessment. Although there is no concensus about the timing, recent data suggests that it may be performed one month after the procedure. However, imaging can be done in the immediate postoperative period, if there are no tubes blurring the assessment. There is some evidence indicating that selective medical therapy may have an impact on decreasing stone formation rates. Retrograde intrarenal surgery, with its minimally invasive nature, seems to be the best way to deal with residual fragments.
\end{abstract}

Key Words: Nephrolithotomy, percutaneous, urinary stones

Received: 16.05.2012 Accepted: 31.08.2012

\section{Introduction}

The main goal of any intervention for urolithiasis is complete stone removal in order to achieve a stone free status. Complete stone removal assures resolution of the immediate adverse outcomes of the stone disease, and prevents possible long-term complications such as pain, obstruction and stone growth. However, after the introduction of Extracorporeal Shock Wave Lithotripsy (ESWL) and the development of endourological interventions including ureterorenoscopy (URS) and percutaneous nephrolithotomy (PCNL), the presence of small residual stones after treatment has been an acceptable therapeutic end point.

Percutaneous nephrolithotomy is an effective procedure which is being considered as the gold standard in the treatment of large/complex renal calculi. Reported stone free rates are up to $90 \%$, probably reflecting the level of experience, stone properties and equipment employed in the procedure. The main reasons for failure of complete stone clearance are inability to access the calyces containing stone fragments, poor visualization due to bleeding, technical problems and stone composition. There are many studies addressing the fate of residual stones, mainly after ESWL, but the residual stones after PCNL are not yet well investigated. In this article, the natural history, diagnosis and management of these stone fragments after PCNL surgery are reviewed.

CIRF or just residual fragments; are they really insignificant? Residual stone fragments are generally defined as stone fragments remaining in the urinary system after the comple- tion of an intervention (ESWL, URS or PCNL). Clinically insignificant residual fragments (CIRFs) are described as asymptomatic, non-infectious and non-obstructive stone fragments $(\leq 4 \mathrm{~mm})$ which can occur in $70 \%$ of patients with large stones undergoing PCNL $(1,2)$. With no treatment, nearly half of these patients will experience a stone-related event, and among them, $50 \%$ of these will need a secondary intervention (3). CIRFs could become eventually significant as nidi for recurrent stone formation; they may cause pain and infection due to significant obstruction, or they may harbor bacteria and become the source of persistent urinary infections (4). There are numerous studies about the significance of these fragments mainly after ESWL, but the results are probably no different from other endourological interventions like PCNL. It is well established that, as the burden of residual fragments increases, the length of follow-up period required, complication rates and need for auxilliary interventions increase as well $(4,5)$.

In a review by Rassweiler et al regarding the role of residual fragments after ESWL; the data and long term results concerning the anatomical kidney situation, stone size, stone localization, and observation period of more than 14000 patients were compared. The authors concluded that CIRFs and clinically significant residual fragments had to be distinguished separately. Newer ESWL technology had increased the percentage of CIRFs and also revealed that 55\% patients with CIRFs would be stone-free or remain clinically insignificant during follow up, only $20 \%$ these would become significant clinically and only $25 \%$ these patients required a secondary intervention, which mostly consisted of a repeat ESWL. 
They concluded that any endoscopic intervention should be considered as over-treatment in the absence of symptoms (6).

Carr et al. (7) revealed a significantly greater rate of stone growth, within 1 year after ESWL, compared with PCNL. For the ESWL group the site of recurrences shifted from baseline to mid and lower calices after the treatment. This trend was not observed in the PCNL patients. As a possible explanation, fine sand debris gravitates to dependent calices and acts as a nidus for stone formation. Also ESWL might lead to stone growth by heterogeneous nucleation and crystal aggregation by increasing the surface area of the stone.

Candau et al. (8) suggested that the term clinically insignificant residual fragments should not be used to define residual stone fragments after ESWL due to the significantly increased rate of complementary treatments. Khaitan et al. (4) reviewed 75 patients with $4 \mathrm{~mm}$ or smaller residual fragments and revealed that $59 \%$ of these patients eventually needed auxilliary interventions. Osman et al. (1) similarly evaluated 173 patients with $4 \mathrm{~mm}$ or smaller residual fragments after ESWL and concluded that $21 \%$ of patients needed retreatment for residual stones.

\section{Natural history of residual fragments after PCNL}

In a study by Ganpule et al., (9) 2469 patients who underwent PCNL were evaluated and residual fragments were identified in $7.57 \%$ of the patients. The assessment of residual stones was made by a combination of ultrasonography and KUB at 48 hours, 1-month and 3 month follow-up. The most common site for residual fragments was the lower calyx (57.7\%), and the mean size of residual fragments was $38.6 \mathrm{~mm}^{2}$. $65.47 \%$ of residual fragments passed spontaneously in 3 months and those $<25 \mathrm{~mm}^{2}$ and in the renal pelvis had the highest chance to pass spontaneously. Metabolic abnormalities (hypercalciuria and hyperuricemia), preoperative nephrostomy drainage, double j stenting, size, the time of presentation of residual fragments and surgeon experience were significant predictive factors.

Raman et al. (10) evaluated 537 patients following PCNL with unenhanced helical CT (UHCT) and 42 (8\%) patients had residual fragments. The most common site of residual frag- ments was the lower pole (47\%) again. The median diameter of the largest fragment was $2 \mathrm{~mm}$ and $60 \%$ (25 of 42) of fragments were $2 \mathrm{~mm}$ or smaller and 79\% (33 of 42) were smaller than $5 \mathrm{~mm}$. They reported that, among 18 patients who experienced a stone-related event, 11 of them (61\%) required a secondary surgical intervention. The major predictors of a stone related event were the stones located in the pelvis or ureter and fragments larger than $2 \mathrm{~mm}$. Beside these, more than $50 \%$ of the patients with a residual stone larger than 2 $\mathrm{mm}$ needed a second- look flexible nephroscopy (FN), which revealed the critical role of maximum stone size compared with cumulative stone size (10).

Altunrende et al. (11) evaluated the 3 year follow-up data of 430 patients who underwent PCNL. The residual fragments were identified in $22 \%$ of the cases and the assessment was made by KUB postoperatively. Those patients with demonstrated residual fragments had an immediate CT scan for exact measurement. Follow-up CT scans were performed annually or when a symptomatic event occurred. Of the patients with residual fragments, $26.3 \%$ had symptomatic events. The most common site was the lower calyx (60.5\%). Metabolic evaluation showed several abnormalities in 10 (26.3\%) patients. Stone analysis revealed magnesium ammonium phosphate in three of eight patients who had an increase in residual fragment size (11). The findings of these studies are summarized in Table 1.

\section{Diagnosis of residual fragments}

Assessment of the size of the stone has an important role in the selection of the treatment modality for stone disease. Traditionally, KUB or ultrasound was used to determine the stonefree status. However, the sensitivity and specificity of these examinations in detecting small residual fragments are low. UHCT is currently considered as the optimal method of assessing the residual stone burden after an endourological intervention. A plain abdominal film (KUB) may overestimate the stone size by $20 \%$ due to magnification error (12). Also, ultrasonography (US) may overestimate the stone size compared with UHCT, especially in stones smaller than $5 \mathrm{~mm}$ (13).

Table 1. Natural history of residual fragments after PCNL

\begin{tabular}{|c|c|c|c|c|c|c|}
\hline Author/year & Pts & \%RFs & $\begin{array}{l}\text { Median } \\
\text { follow up }\end{array}$ & $\begin{array}{c}\text { Stone related } \% \\
\text { events }\end{array}$ & $\begin{array}{c}\text { Major risk } \\
\text { factors }\end{array}$ & Diagnosis \\
\hline $\begin{array}{l}\text { Ganpule } \\
2008\end{array}$ & 2469 & $7.57 \%$ & 24 months & - & $\begin{array}{l}\text { Pre-op. drainage } \\
\text { JJ stenting } \\
\text { Size of RFs } \\
\text { ne of presentation of RFs } \\
\text { Surgeon experience } \\
\text { Hypercalciuria } \\
\text { Hyperuricosuria }\end{array}$ & $\begin{array}{l}\text { KUB+US } \\
(48 \mathrm{~h}, 1 \mathrm{mo}, 3 \mathrm{mo}) \\
\mathrm{CT}\end{array}$ \\
\hline $\begin{array}{l}\text { Raman } \\
2009\end{array}$ & 537 & $8 \%$ & 41 months & $43 \%$ & $\begin{array}{l}\text { RFs larger than } 2 \mathrm{~mm} \\
\text { Location of RFs in } \\
\text { pelvis or ureter }\end{array}$ & CT \\
\hline $\begin{array}{l}\text { Altunrende } \\
2010\end{array}$ & 430 & $22 \%$ & 28.4 months & $26.4 \%$ & Struvite stones & $\begin{array}{l}\text { KUB (Post-op) } \\
\text { CT (on KUB+ } \\
\text { or when symptoms } \\
\text { occur or annually) }\end{array}$ \\
\hline
\end{tabular}


The superiority of linear renal tomography over plain radiographs for detecting nephrolithiasis was well demonstrated $(14,15)$. Sacks et al. (16) compared plain abdominal radiographs versus digital renal tomograms for detecting calculi in patients who underwent ESWL and concluded that calculus detection by digital tomography was superior to detection by KUB (16). Jewett et al. (17) revealed that KUB alone was frequently difficult to interpret, resulting in uncertainty about the presence of residual fragments. Tomogram alone or plain abdominal x-ray plus tomograms are superior to plain abdominal $x$-ray alone. US is usually considered a poor diagnostic tool for detecting retained calculi compared with other imaging modalities. Palmer et al. (18) reported that US failed to detect stones in $41 \%$ of children with urolithiasis, but CT was highly reliable in all situations. Thin slice UHCT, combined with image.

Reconstruction, showed higher sensitivity for the detection of residual stones when it was prospectively compared to other imaging modalities. The sensitivity of the UHCT was almost $100 \%$ compared to $47.6 \%$ for KUB, $89.2 \%$ for linear tomography and $67.8 \%$ for US (5-19). UHCT, despite its high sensitivity and specificity in stone detection, is not perfect. Beyond exposure to radiation and its cost, data showed that UHCT may overestimate the stone size in the cranio-caudal dimension (20).

Osman et al. (5) evaluated the accuracy of unenhanced spiral CT in the detection of residual fragments after PCNL. They evaluated 100 renal units after $P C N L$, including 55 opaque and 45 radiolucent stones by KUB, US and UHCT, and found the sensitivity for detecting significant fragments as $100 \%$ for CT, $20 \%$ for plain $x$-ray, $20 \%$ for ultrasound and $33.3 \%$ for linear tomography. For opaque stones, sensitivity for overall stone detection was $100 \%$. Sensitivity for detecting significant residual stones was $100 \%$ for spiral computerized tomography, $85.7 \%$ for plain $x$-ray ( $p$ is not significant), $95.2 \%$ for linear tomography. The authors concluded that UHCT was the most sensitive tool for residual fragments after PCNL. However, there was no need to routinely perform this in patients with opaque stones since it yielded no statistically significant increase in the diagnosis of residual stones compared with other imaging modalities.

CT seems to be the optimal imaging modality, but when it comes to the other important question, the ultimate time for imaging after PCNL, the data is not conclusive. Eisner et al considered that employing laser lithotripsy during URS or PCNL might not reflect total stone clearance, if imaging is performed within 1-2 weeks postoperatively, since very small fragments might pass during and after ureteral stent placement. Also, the fragments spontaneously passing down to the ureter could be easily detected as residual fragments by CT (21). Therefore imaging 1 month after PCNL seems optimal. Imaging after a month may have advantages over more immediate imaging, since the residual stones may be obscured by ureteral stents and nephrostomy tubes (22). However, if PCNL is being performed with active extraction, imaging can be done immediately if there are no tubes blurring the assessment.

\section{Prevention of residual fragments during PCNL}

Some authors described several approaches in order to prevent residual fragments after PCNL. Hemal et al. (23) re- searched the impact of single and multiple pulse settings of pneumatic lithotripsy and revealed that a single pulse mode provided more controlled fragmentation, creating larger stones that could be extracted which would decrease the probability of residual stones.

\section{Multi-tract PCNL}

The American Urological Association has suggested that two or more access sites may be required in the treatment of large or complex stones (24). After utilisation of new instruments like flexible ureterorenoscopes combined with standard PCNL, there is a decrease in using multi-tracts for treating renal calculi due to slightly increased blood loss and complications. Hegarty et al. (25) compared the outcomes of single tract $\mathrm{PCNL}$ versus multitract $\mathrm{PCNL}$ in a prospective study ( $n=20$ in each group). The stone free rates were $100 \%$ for single tract PCNL and 95\% for the multiple-tract patients. The mean blood loss was similar in both groups. In another study by Aron et al. (26) with one hundred and twenty-one renal units, the stone-free rate was $80.0 \%$ with lower and middle-caliceal punctures, $87.5 \%$ with upper caliceal puncture, and $84.8 \%$ with multiple access tracts. Bleeding requiring transfusion was significantly more common in the multipletract group. Akman et al. (27) compared 413 patients who underwent PCNL. 244 (59\%) patients were treated by single access (Group 1); while multiple accesses were necessary in 169 (41\%) patients (Group 2). Stone free rates were $70.1 \%$ in group 1 and $81.1 \%$ for group 2 after PCNL. The most frequent complication was blood loss for both groups, which was higher in group 2 but there were no significant differences in the other complications between the two groups.

There is little difference in complication rates utilizing multiple accesses but the multiple-tract approach has the advantage of creating stone free status without increasing the cost, and the latter may be the most important issue in countries with lower socioeconomic levels while performing PCNL. Creating multiple tracts does not require a learning curve to be overcome.

\section{Management of Residual Fragments After PCNL}

\section{Medical therapy}

Medical therapy of residual fragments after PCNL is not well established and current data is mainly from published work on ESWL. However, there are a few studies suggesting that medical therapy can work in residual fragments after PCNL under some circumstances. Kang et al. (28) evaluated the effect of medical therapy on stone formation in 70 patients who underwent PCNL and received medical management. They found that selective medical therapy significantly decreased stone formation rates in the stone-free groups and those with residual fragments and also, remission was observed in a higher proportion of patients in the medically treated stone-free group and the group with residual fragment groups, when compared to similar groups not receiving medical therapy.

Lojanapiwat et al. (29) evaluated 76 patients with calcium stones who underwent ESWL $(n=50)$ and PCNL $(n=26)$ and 
randomised them into medical therapy (alkaline citrate) and no treatment groups. The subjects were followed up for 12 months and it was found that the stone-free status and unchanged stone size status were significantly more frequent in the treated group (5.3 fold in stone-free patients and 1.38 fold in CIRF patients as compared to the untreated group) and pointed out the efficacy of alkaline citrate treatment in $\mathrm{Ca}$ stone formers following ESWL and PCNL.

\section{ESWL}

Combination therapy of ESWL+PCNL gained popularity in the past but, due to development in endovisual and lithotriptor technologies, it is now considered as more expensive and time consuming with no better efficacy $(30,31)$.

\section{$2^{\text {nd }}$ look nephroscopy}

Development of flexible nephroscopes allowed surgeons to reach parts of the collecting system far better than with rigid instruments and facilitated more careful inspection of the whole collecting system. However, current data concerning the standard use of these flexible instruments is not clear.

Denstedt et al. (32) recommended routine direct inspection of the entire collecting system with flexible nephroscopy using local anesthesia and intravenous sedation to provide a more accurate assessment of kidney stone-free status. They considered this procedure the gold standard for diagnosing residual stones after PCNL. Nevertheless, this approach was later contradicted by Pearle et al., (33) who recommended restricting the liberal use of flexible nephroscopy in patients with positive CT findings. Pearle et al. (33) based their conclusion on the equal sensitivity of CT and high optical resolution flexible endoscopy with the advantage of avoiding unnecessary fluoroscopic exposure as well as decreased costs, hospital stay and complication rate.

\section{Retrograde intrarenal surgery}

Due to technological improvements in flexible ureteroscopes such as the incorporation of a working channel, decrease in the diameter of the scope and the other improvements in vision, retrograde intrarenal surgery (RIRS) gained popularity throughout the last decade and is being seriously considered as an alternative to $\operatorname{PCNL}(34,35)$. As the primary treatment in 2-4 cm stones, Akman et al found stone-free rates after one session as $73.5 \%$ and $91.2 \%$ for RIRS and PCNL respectively (36). Stone-free rate in the RIRS group rose to $88.2 \%$ after the second procedure. However, high costs and need for multiple sessions still seem major drawbacks.

The technique and first major series of supine PCNL (sPCNL) was described and reported by Valdivia-Uria and then the technique was improved by Ibarluzea $(37,38)$. As a combined procedure with PCNL, Scaffone et al. (39) treated 127 patients with mean $23.8 \mathrm{~mm}$ urinary stones in the Galdakaomodified supine Valdivia position, which allows simultaneous application of PCNL and retrograde ureteroscopy (ECIRS, Endoscopic Combined Intra-Renal Surgery) with a stone free rate of $81.95 \%$ after the first intervention. In a recent study, Hoznek et al. (40) evaluated 47 patients with kidney stones $>2$ $\mathrm{cm}$ who underwent simultaneus PCNL and RIRS in the Galda- kao-modified supine Valdivia position. Only 9 patients needed a second intervention, with success rates reaching $100 \%$ at 3 months and concluded that SPCNL was a further advancement in stone surgery, offering the advantage of simultaneous retrograde and antegrade endoscopic combined intrarenal surgery. Although this combined procedure seems easier and better from the anesthetist's point of view than the traditional prone approach, stone free rates are similar to standard PCNL procedures in a limited series of patients. It is a relatively new procedure which is increasingly gaining popularity, and with a larger series of patients with longer follow-up, the comparisons would be much more conclusive.

\section{Residual fragments in children}

Pediatric PCNL was first described in children in 1985 by Woodside et al. (41) who performed PCNL with $100 \%$ stone removal in one session, using standard adult instruments (24$34 \mathrm{~F}$ ) in seven children. PCNL in children become easier after Jackman et al. (42) introduced the mini-perc technique using an $11 \mathrm{~F}$ instrument. Evolution of pediatric PCNL techniques such as mini-perc, diminished tract size and advanced intracorporeal lithotripters have made this a popular technique for achieving stone-free status in selected patients. Pediatric PCNL complete stone free rates are becoming closer to that in adults, as the numbers in the current literature range between $86.9 \%$ and $98.5 \%(43,44)$.

The natural history of residual fragments in children is not well known and is estimated as the same as adult urolithiasis, which may not be similar for pediatric cases. Afshar et al. (45) evaluated the consequences of residual fragments following ESWL in the pediatric population. The data of 39 boys and 44 girls with a median age of 7 years and a mean follow up of 46 months who underwent ESWL were analysed. After the intervention 18 patients (20\%) had residual fragments of $5 \mathrm{~mm}$ or less and 30 (34\%) renal units required further treatment. After a secondary intervention, 12 of them were stone-free and eight still had residual fragments. Of the children with residual fragments smaller than $5 \mathrm{~mm}$ (26 renal units), 18 of them (69\%) had adverse clinical outcomes like growth of residual stones and pain episodes. Compared to stone free cases, the patients with residual stones had a significant increase in adverse clinical outcomes. Metabolic disorders were significantly associated with the growth of residual fragments. They concluded that residual stones after ESWL significantly increase the chance of adverse clinical outcome and they need to be followed up closely, particularly in those children with identifiable predisposing disorders.

\section{Conclusion}

CIRFs is not a suitable term after PCNL or any other intervention, since a significant portion of these are likely to develop a stone related event and most of them will have additional procedures. Efforts should be performed to achieve complete stone-free status after any urologic intervention for urinary stone disease. Also it is important to inform all patients who are to have PCNL surgery about the consequences of residual stones, such as the risk of a symptomatic stone episode 
or the eventual need for auxilliary therapies. CT is the ultimate choice for imaging and the best method of management of residual stones after PCNL seems to be flexible ureterorenoscopy since it is less invasive than second look nephroscopy. The higher rates of complete stone removal of recent PCNL series and RIRS, alone or combined with PCNL, seem really encouraging. Therefore, it is not optimistic to conclude that future is looking bright for stone surgery.

\section{Conflict of Interest}

No conflict of interest was declared by the authors.

\section{References}

1. Osman MM, Alfano Y, Kamp S, Haecker A, Alken P, Michel MS, et al. 5-year follow-up of patients with clinically insignificant residual fragments after extracorporeal shockwave lithotripsy. EurUrol 2005;47:860-4. [CrossRef]

2. Pearle MS, Watamull LM, Mullican MA. Sensitivity of noncontrast helical computerized tomography and plain film radiography compared to flexible nephroscopy for detecting residual fragments after percutaneous nephrostolithotomy. J Urol 1999;162:23-6. [CrossRef]

3. Skolarikos A, Papatsoris AG. Diagnosis and management of postpercutaneous nephrolithotomy residual stone fragments. JEndourol 2009;23:1751-5. [CrossRef]

4. Daggett LM, Harbaugh BL, Collum LA. Post-ESWL, clinically insignificant residual stones: Reality or myth? Urology 2002;59:20-4. [CrossRef]

5. Osman Y, El-Tabey N, Refai H, Elnahas A, Shoma A, Eraky l, et al. Detection of residual stones after percutaneous nephrolithotomy: Role of noneennhanced spiral computerized tomography. J Urol 2008;179:198-200. [CrossRef]

6. Rassweiler JJ, Renner C, Chaussy C, Thuroff S. Treatment of renal stones by extracorporeal shockwave lithotripsy: an update. EurUrol 2001; 39:187- 99. [CrossRef]

7. Carr LK, D'A Honey J, Jewett MA, Ibanez D, Ryan M, Bombardier C. New stone formation: A comparison of extracorporeal shock wave lithotripsy and percutaneous nephrolithotomy. J Urol 1996;155:1565-7. [CrossRef]

8. Candau C, Saussine C, Lang H, Roy C, Faure F, Jacamin D. Natural history of residual renal stone fragments after ESWL. EurUrol 2000;37:18-22. [CrossRef]

9. Ganpule A, Desai M. Fate of residual stones after percutaneous nephrolithotomy: A critical analysis. J Endourol2009; 23:399-403. [CrossRef]

10. Raman JD, Bagrodia A, Gupta A, Bensalah K, Cadeddu JA, Lotan $Y$, et al. Natural history of residual fragments following percutaneous nephrostolithotomy. J Urol 2009;181:1163-8. [CrossRef]

11. Altunrende F, Tefekli A, Stein RJ, Autorino R, Yuruk E, Laydner $\mathrm{H}$, et al. Clinically insignificant residual fragments after percutaneous nephrolithotomy: medium-term follow-up. J Endourol 2011;25:941-5. [CrossRef]

12. Olcott EW, Sommer FG, Napel S. Accuracy of detection and measurement of renal calculi: in vitro comparison of three-dimensional spiral CT, radiography and nephrotomography. Radiology. 1997;204:19-25.

13. Ray AA, Ghiculete PKT, Honey RJ. Limitations to ultrasound in the detection and measurement of urinary tract calculi. Urology 2010;76:295-300. [CrossRef]

14. Dundee P, Bouchier-Hayes D, Haxhimolla H, Dowling R, Costello A. Renal tract calculi: comparison of stone size on plain radiography and noncontrast spiral CT scan. J Endourol 2006;20:1005-9. [CrossRef]

15. Van Appledorn S, Ball AJ, Patel VR, Kim S, Leveillee RJ. Limitations of noncontrast CT for measuring ureteral stones. J Endourol 2003;17:851-4. [CrossRef]
16. Sacks E, Fajardo L, Hillman B, Drach G, Gaines J, Claypool H, et al: Prospective comparison of plain abdominal radiography with conventional and digital renal tomography in assessing renal extracorporeal shock wave lithotripsy patients. J Urol 1990;144:1341-6.

17. Jewett M, Bombardier C, Caron D, Ryan M, Gray R, St. Louis E, et al. Potential for inter-observer and intra-observer variability in $\mathrm{x}$-ray review to establish stone-free rates after lithotripsy. J Urol 1992; 147:559-62.

18. Palmer J, Donaher E, O'Riordan M and Dell K. Diagnosis of pediatric urolithiasis: role of ultrasound and computerized tomography. J Urol 2005;174:1413-6. [CrossRef]

19. Park J, Hong B, Park T, Park HK. Effectiveness of non- contrast computed tomography in evaluation of residual stones after percutaneous nephrolithotomy. J Endourol 2007;21:684-7. [CrossRef]

20. Jackman SV, Potter SR, Regan F, Jarrett TW. Plain abdominal xray versus computerized tomography screening: sensitivity for stone localization after nonenhanced spiral computerized tomography. J Urol 2000;164:308-10. [CrossRef]

21. Eisner BH, McQuaid JW, Hyams E, Matlaga BR. Nephrolithiasis: what surgeons need to know. AJR 2011;196:1274-8. [CrossRef]

22. Portis AJ, Laliberte MA, Holtz C, Ma W, Rosenberg MS, Bretzke CA. Confident intra- operative decision making during percutaneous nephrolithotomy: Does this patient need a second look? Urology 2008;71:218-22 [CrossRef]

23. Hemal AK, Goel A, Aron M, Seth A, Dogra PN, Gupta NP. Evaluation of fragmentation with single or multiple pulse setting of Lithoclast for renal calculi during percutaneous nephrolithotripsy and its impact on clearance. Urol Int 2003;70:265-8. [CrossRef]

24. Preminger GM, Assimos DG, Lingeman JE. AUA guideline on management of staghorn calculi: diagnosis and treatment recommendations. J Urol 2005;173:1991-2000. [CrossRef]

25. Hegarty NJ, Desai MM. Percutaneous nephrolithotomy requiring multiple tracts: comparison of morbidity with single-tract procedures. J Endourol 2006;20:753-60. [CrossRef]

26. Aron M, Yadav R, Goel R, Kolla SB, Gautam G, Hemal AK, et al. Multi tract percutaneous nephrolithotomy for large complete staghorn calculi. Urollnt 2005;75:327-32. [CrossRef]

27. Akman T, Sari E, Binbay M, Yuruk E, Tepeler A, Kaba M, et al. Comparison of Outcomes After Percutaneous Nephrolithotomy of Staghorn Calculi in Those with Single and Multiple Accesses J Endourol. June 2010;24:955-60.

28. Kang DE, Maloney MM, Haleblian GE, et al. Effect of medical management on recurrent stone formation following percutaneous nephrolithotomy. J Urol 2007;177:1785-9. [CrossRef]

29. Lojanapiwat B; Tanthanuch M; Pripathanont C; Ratchanon S; Srinualnad S; Taweemonkongsap T; Kanyok S; Lammongkolkul. Alkaline citrate reduces stone recurrence and regrowth after shockwave lithotripsy and percutaneous nephrolithotomy. Int. braz j urol. vol.37 no.5 Rio de Janeiro Sept.Oct. 2011

30. Streem SB, Yost A, Dolmatch B. Combination "sandwich" therapy for extensive renal calculi in 100 consecutive patients: Immediate, long-term and stratified results from a 10 -year experience. J Urol 1997;158:342-5. [CrossRef]

31. Merhej S, Jabbour M, Samaha E, Chalouhi E, Moukarzel M, Khour $\mathrm{R}$, et al. Treatment of staghorn calculi by percutaneous nephrolithotomy and SWL: The Hotel Dieu de France experience. J Endourol 1998;12:5-8. [CrossRef]

32. Denstedt JD, Clayman RV, Picus DD. Comparison of endoscopic and radiological residual fragment rate following percutaneous nephrolithotripsy. J Urol 1991;145:703-5.

33. Pearle MS, Watamull LM, Mullican MA. Sensitivity of non- contrast helical computerized tomography and plain film radiography compared to flexible nephroscopy for detecting residual fragments after percutaneous nephrostolithotomy. J Urol 1999;162:23-6. [CrossRef] 
34. Breda A, Ogunyemi O, Leppert JT, Lam JS, Schulam PG. Flexible ureteroscopy and laser lithotripsy for single intrarenal stones $2 \mathrm{~cm}$ or greater - is this the new frontier? J Urol 2008;179:981-4. [CrossRef]

35. Traxer O, Dubosq F, Jamali K, Gattegno B, Thibault P. New- generation flexible ureterorenoscopes are more durable than previous ones. Urology 2006;68:276-80. [CrossRef]

36. Akman $\mathrm{T}$, Binbay $\mathrm{M}, \mathrm{Ozg}$ or $\mathrm{F}$ et al. Comparison of percutaneous nephrolithotomy and retrograde flexible nephrolithotripsy for the management of 2-4 cm stones: a matched-pair analysis. BJU Int 2011.

37. Valdivia Uría JG, Valle Gerhold J, López López JA, Villarroya Rodriguez S, Ambroj Navarro C, Ramirez Fabián M, et al. Technique and complications of percutaneous nephroscopy: experience with 557 patients in the supine position. J Urol 1998;160:1975-8. [CrossRef]

38. Ibarluzea G, Scoffone CM, Cracco CM, Poggio M, Porpiglia F, Terrone $C$, et al. Supine Valdivia and modified lithotomy position for simultaneous anterograde and retrograde endourological access. BJU Int 2007;100:233-6. [CrossRef]

39. Scoffone CM, Cracco CM, Cossu M, Grande S, Poggio M, Scarpa RM. Endoscopic combined intrarenal surgery in Galdakao-modified supine Valdivia position: a new standard for percutaneous nephrolithotomy? EurUrol 2008;54:1393-403. [CrossRef]
40. Hoznek A, Rode J, Ouzaid I, Faraj B, Kimuli M, de la Taille A, et al. Modified Supine Percutaneous Nephrolithotomy for Large Kidney and Ureteral Stones: Technique and Results. EurUrol 2012;61:164-70. [CrossRef]

41. Woodside JR, Stevens GF, Stark GL, Borden TA, Ball WS. Percutaneous stone removal in children.J Urol 1985;134:1166-7.

42. Jackman SV, Hedican SP, Peters CA, Docimo SG. Percutaneous nephrolithotomy in infants and preschool age children: experience with a new technique. Urology 1998;52:697-701. [CrossRef]

43. Desai MR, Kukreja RA, Patel SH, Bapat SD. Percutaneous nephrolithotomy for complex pediatric renal calculus disease. J Endourol 2004;18:23-7. [CrossRef]

44. Dawaba MS, Shokeir AA, Hafez AT, Shoma AM, El-Sherbiny MT, Mokhtar A, et al. Percutaneous nephrolithotomy in children: early and late anatomical and functional results. J Urol 2004;172:1078-81. [CrossRef]

45. Afshar K, McLorie G, Papanikolaou F, Malek R, Harvey E, PippiSalle JL, et al. Outcome of small residual stone fragments following shock wave lithotripsy in children. J Urol 2004;172:1600-3. [CrossRef] 